\title{
Overweight and obesity prevalence in referral population of infertile women with polycystic ovary syndrome
}

\begin{abstract}
Background: Obesity and polycystic ovary syndrome are commonly associated, but data regarding overweight and obesity prevalence in PCOS patients remains controversial and depends on study population (referral or unselected) and PCOS phenotype. There are few studies which present ethnic differences in prevalence of overweight and obese women with PCOS.
\end{abstract}

Objective: To test the hypothesis that overweight and obesity prevalence is not similar in infertile women with PCOS and without PCOS and depends on ethnicity of patients.

Subjects and methods: A prospective study was performed in a referral (clinical) population, included 397 infertile women (134 with PCOS, aged 28.2 \pm 4.7 years (Group A) and 263 without PCOS, aged 29.4 \pm 5.4 years (Group B); 363 Caucasians and 34 Asians), who were referred for the evaluation of infertility at clinical research centers in Irkutsk and Ulan-Ude (Eastern Siberia) between 2007 and 2015, and agreed to participate in the prospective study. 53 fertile women aged 27.6 7 .3years were recruited as controls. A complete medical history, physical examination with BMI calculation, laparoscopy, pelvic ultrasound and hormonal immunoassay analysis were performed in all patients.

Results: The mean BMI and obesity prevalence was significantly higher in both groups of infertile patients compared to controls without significant difference between women with PCOS and without PCOS. However, lower rate of subjects with normal BMI was demonstrated predominantly in the PCOS group. The increase of mean BMI vs controls was more significant in Asian infertile women with PCOS than in Caucasians.

Conclusion: Our study results suggest that the mean BMI and obesity prevalence are comparable in the referral population of infertile women with and without PCOS. Nevertheless, the lower number of patients with normal BMI, compared to fertile controls, have been found only in the group of PCOS infertile women. These findings may be explained by phenotype and ethnic heterogeneity of PCOS women. Asian infertile women with PCOS are more likely to have increased BMI than Caucasians. Due to study limitations more data is needed in referral as well as in unselected populations of PCOS women from Asian and Caucasian ethnic groups.

Keywords: overweight, obesity, prevalence, ethnicity
Volume 7 Issue I - 2017

Suturina LV,' Atalyan AV,' Darzhaev ZY,' Belenkaya LV,' Baldano MN, ${ }^{2}$ Lazareva LM' 'Scientific Center for Family Health and Human Reproduction, Russia

${ }^{2}$ The Institute for Mongolian, Buddhist and Tibetan Studies, Russia

Correspondence: Suturina LV, Department of Reproductive Health Protection, Scientific Center for Family Health and Human Reproduction, Timiryazeva str., 16, Irkutsk, 664003, Russia,Email Isuturina@mail.ru

Received: June 15, 2017 | Published: July 18, 2017
Abbreviations: PCOS, polycystic ovary syndrome; BMI, body mass index

\section{Introduction}

Polycystic ovary syndrome (PCOS) is one of the most common endocrine disorders affecting women of reproductive age worldwide. ${ }^{1,2}$ The diagnosis of PCOS is based on the ESHRE/ASRM 2003 criteria, ${ }^{3,4}$ with a detailed description of the PCOS phenotype..$^{5,6}$ PCOS is characterized by a spectrum of clinical manifestations and associated morbidities. Previously it was reported that obesity is more prevalent in women with PCOS compare to patients without PCOS, however, the data on overweight and obesity incidence in PCOS patients remains controversial and depends on PCOS phenotype and study population (referral or unselected). It has been shown that PCOS patients from referral population have a greater mean BMI and higher prevalence of obesity compared to women with PCOS diagnosed in the medically unselected population. ${ }^{7-12}$

The evidence that obesity is associated with higher prevalence of PCOS is conflicting too. Data from some retrospective and longitudinal observational studies have suggested the higher incidence of PCOS among obese women, but it was not supported by data obtained in other studies. ${ }^{13-18}$ Racial and ethnic characteristics are very important aspects to be considered in PCOS but there are few studies reported ethnic differences in overweight and obesity prevalence among women with PCOS..$^{19-22}$ Siberia is a unique region where Caucasian and Asian populations live in similar geographic and socio-economic conditions since the $17^{\text {th }}$ century. The main ethnic groups in Eastern Siberia are Russians (Caucasians) and Buryats (Asians). However, the ethnic impact on BMI in PCOS patients in Siberia have not been adequately investigated. 


\section{Objective}

To test the hypothesis that overweight and obesity prevalence is not similar in infertile women with PCOS and without PCOS and depends on ethnicity of patients.

\section{Subjects and study design}

A prospective study was performed in a referral (clinical) population, included 397 infertile women (134 with PCOS (Group A) and 263 without PCOS (Group B); 363 Caucasians and 34 Asians), who were referred for the evaluation of infertility at clinical research centers in Irkutsk and Ulan-Ude (Eastern Siberia) between 2007 and 2015, and agreed to participate in the prospective study. 53 fertile premenopausal women were recruited as controls.

\section{Methods}

A complete medical history, physical examination, laparoscopy, pelvic $\mathrm{U} / \mathrm{S}$ and hormonal immunoassay analysis (for total testosterone, DHEAS, LH, FSH, prolactin, TSH, and 17-hydroxyprogesterone) were performed using a standardized protocol in all infertile women to verify infertility causes. Hirsutism was defined by a modified Ferriman-Gallwey (mFG) hirsutism score $>6$ in Caucasians and $>4$ in Asians. Menstrual dysfunction (MD) was defined as menstrual cycles $\geq 35$ and/or $\leq 23$ days. Polycystic ovarian morphology (PCO) was defined as an antral follicle count ( $2-9 \mathrm{~mm}$ diameter $) \geq 12$ and/or an ovarian volume of $\geq 10 \mathrm{~cm}^{3}$. Body mass index (BMI) was calculated on the basis of weight (kilograms) and height (meters). Subjects with BMI $25-29.9 \mathrm{~kg} / \mathrm{m}^{2}$ were classified as overweight, and with BMI $\geq 30 \mathrm{~kg} / \mathrm{m}^{2}$ as obese. The study was approved by the Institutional Review Board of the Scientific Center of Family Health and Human Reproduction Problems. All subjects gave written informed consent. ANOVA, Mann-Witney test, $\chi 2$ test and the Fisher's exact test were used for statistical analysis, p-value less than 0.05 were considered as statistically significant.

\section{Results}

Baseline characteristics of the study population are presented in the Table 1 . The data indicate that the mean BMI and obesity prevalence were significantly higher in both groups of infertile patients compared to controls without any difference between women with PCOS and without PCOS. However, only in the group A, consisted of PCOS subjects, the number of women with normal BMI was significantly lower in comparison with fertile controls. As shown in the Table 2, the difference in overweight and obesity in PCOS and non-PCOS women has not reached significance in Asian (Buryat) as well as in Caucasian (Russian) patients (all $\mathrm{p}>0.05$ ). However, the increase of mean BMI vs controls was more significant in Asian infertile women with PCOS than in Caucasians (Table 3).

Table I Age and anthropometric characteristics of study population

\begin{tabular}{llll}
\hline Variables & $\begin{array}{l}\text { Group A (PCOS) } \\
\mathbf{n}=1 \mathbf{3 4}\end{array}$ & $\begin{array}{l}\text { Group B (without PCOS) } \\
\mathbf{n}=\mathbf{2 6 3}\end{array}$ & $\begin{array}{l}\text { Controls } \\
\mathbf{n}=\mathbf{5 3}\end{array}$ \\
\cline { 2 - 4 } & $\mathbf{I}$ & $\mathbf{2}$ & $\mathbf{3}$ \\
\hline Age (years, mean \pm SD) & $28.2 \pm 4.7$ & $29.4 \pm 5.4$ & $27.6 \pm 7.3$ \\
BMI $\left(\mathrm{kg} / \mathrm{m}^{2}\right.$, mean \pm SD) & $25,7 \pm 5,7^{* *}$ & $25,1 \pm 5,4^{*}$ & $23,2 \pm 3,1$ \\
BMI lower than I8kg/m², $(\%)$ & $6(4.5)$ & $7(2.7)$ & $1(1.9)$ \\
Normal BMI $\left(18-24.9 \mathrm{~kg} / \mathrm{m}^{2}\right), \mathrm{n}(\%)$ & $67(50)^{\#}$ & $148(56.3)$ & $37(69.8)$ \\
Overweight $\left(25-29.9 \mathrm{~kg} / \mathrm{m}^{2}\right), \mathrm{n}(\%)$ & $33(24.6)$ & $62(23.6)$ & $12(22.6)$ \\
Obese $\left(\geq 30.0 \mathrm{~kg} / \mathrm{m}^{2}\right), \mathrm{n}(\%)$ & $28(20.9)^{\#}$ & $46(17.5)^{\#}$ & $3(5.7)$ \\
\hline
\end{tabular}

${ }^{*} \mathrm{P}_{\mathrm{U}}<0,05 ;{ }^{* *} \mathrm{P}_{\mathrm{U}}<0,01 ;{ }^{\#} \mathrm{P}_{\chi^{2}}<0,05 ;{ }^{\#} \mathrm{P}_{\chi^{2}}<0,01$, compared to controls

Table 2 Characteristics of Caucasian and Asian PCOS and non-PCOS infertile women from study population

\begin{tabular}{|c|c|c|c|c|}
\hline \multirow{2}{*}{ Variables } & \multicolumn{2}{|c|}{ Caucasians $n=363$} & \multicolumn{2}{|l|}{ Asians $n=34$} \\
\hline & $P \cos n=123$ & Without PCOS n=240 & $P \cos n=11$ & Without PCOS $n=23$ \\
\hline Age (years, mean $\pm S D$ ) & $28.3 \pm 4.8$ & $29.2 \pm 5.4$ & $28.3 \pm 4.4$ & $32.1 \pm 4.9$ \\
\hline BMI $\left(\mathrm{kg} / \mathrm{m}^{2}\right.$, mean $\left.\pm \mathrm{SD}\right)$ & $25.6 \pm 5.8$ & $25.2 \pm 5.5$ & $26.5 \pm 5.9$ & $23.9 \pm 4.7$ \\
\hline BMI lower than $18 \mathrm{~kg} / \mathrm{m}^{2}, \mathrm{n}(\%)$ & $6(4.9)$ & $6(2.5)$ & 0 & I (4.3) \\
\hline Normal BMI (I8-24.9kg/m²), n (\%) & $62(50.4)$ & $136(56.7)$ & $5(45.4)$ & $12(52.2)$ \\
\hline Overweight $\left(25-29.9 \mathrm{~kg} / \mathrm{m}^{2}\right), \mathrm{n}(\%)$ & $29(23.6)$ & $54(22.5)$ & $4(36.4)$ & $8(34.8)$ \\
\hline Obese $\left(\geq 30.0 \mathrm{~kg} / \mathrm{m}^{2}\right), \mathrm{n}(\%)$ & $26(21.1)$ & $44(18.3)$ & $2(18.2)$ & $2(8.7)$ \\
\hline
\end{tabular}


Table 3 Age and BMI of Caucasian and Asian infertile women with PCOS and controls

\begin{tabular}{|c|c|c|c|c|}
\hline \multirow{3}{*}{ Variables } & \multirow{2}{*}{\multicolumn{2}{|c|}{ Caucasians }} & & \\
\hline & & & \multicolumn{2}{|l|}{ Asians } \\
\hline & $\begin{array}{l}\text { PCOS } \\
n=123\end{array}$ & $\begin{array}{l}\text { Controls } \\
n=33\end{array}$ & $\begin{array}{l}\text { PCOS } \\
n=1 \mid\end{array}$ & $\begin{array}{l}\text { Controls } \\
n=23\end{array}$ \\
\hline Age (years, mean $\pm S D)$ & $28.3 \pm 4.8$ & $27.4 \pm 6.6$ & $28.3 \pm 4.4$ & $28.4 \pm 8.2$ \\
\hline BMI $\left(\mathrm{kg} / \mathrm{m}^{2}\right.$, mean $\left.\pm \mathrm{SD}\right)$ & $25.6 \pm 5.8^{*}$ & $23.4 \pm 4.2$ & $26.5 \pm 5.9 * *$ & $22.9 \pm 2.9$ \\
\hline
\end{tabular}

$*_{\mathrm{p}}: 0,05 ; *^{*} \mathrm{p}: 0,01$, compared to controls.

\section{Discussion}

Obesity is a well known cause of menstrual cycle abnormalities, ovulatory disorders and infertility. Even though many obese people are fertile, BMI strongly contributes to the risk of impaired fertility and weight loss significantly increases the chances of getting pregnant. ${ }^{23}$ It was previously demonstrated that prevalence of obesity in PCOS women is significant, correlates with severity of hyperandrogenism and exacerbates insulin resistance. ${ }^{10}$ At the same time some authors reported that the prevalence of metabolic syndrome does not differ in obese vs non-obese women with PCOS. This may be explained by the heterogeneity of the groups of infertile women due to different causes of infertility, PCOS phenotype and racial differences.

Our data has shown that obesity rate in fertile controls is significantly lower than in women with infertility regardless of PCOS presence. These findings did not depend on race: the prevalence of overweight and obesity in PCOS and non-PCOS women was comparable in Asian as well as in Caucasian infertile patients. Our results are not conflicting with recently reported data from Jordan, where was no statistically significant difference in BMI in infertile women with and without PCOS. However, in our study Asian PCOS patients demonstrated more significant increase of mean BMI compared to fertile controls than Caucasian women with PCOS. In our opinion, this emphasizes the importance of race when considering potential associations of PCOS and obesity and their interaction.

\section{Study strength}

Our study design allowed us to estimate overweight and obesity prevalence in infertile women with PCOS and without PCOS whilst taking into account their race. The main study limitations were as follows: only infertile patients were recruited in this study; a size of the group of Asian (Buryat) women with PCOS was relatively small due to lower rate of Buryats in the general population of Eastern Siberia; we used immunoassay method of androgen detection, whereas a mass spectrometry method is preferred.

\section{Conclusion}

Our study results suggest that the mean BMI and obesity prevalence are comparable in the referral population of infertile women with and without PCOS. Nevertheless, the lower number of patients with normal BMI, compared to fertile controls, have been found only in the group of PCOS infertile women. These findings may be explained by phenotype and ethnic heterogeneity of PCOS women. Asian infertile women with PCOS are more likely to have increased BMI than Caucasians. Due to study limitations more data on the ethnicity impact of PCOS on overweight and obesity is needed in referral as well as in unselected populations of PCOS women from Asian and Caucasian ethnic groups.

\section{Acknowledgements}

None.

\section{Conflict of interest}

The author declares no conflict of interest.

\section{References}

1. Azziz R, Woods KS, Reyna R, et al. The prevalence and features of the polycystic ovary syndrome in an unselected population. $J$ Clin Endocrinol Metab. 2004;89(6):2745-2749.

2. Yildiz BO, Bozdag G, Yapici Z, et al. Prevalence, phenotype and cardiometabolic risk of polycystic ovary syndrome under different diagnostic criteria. Hum Reprod. 2012;27(10):3067-3073.

3. Rotterdam EA. Revised 2003 consensus on diagnostic criteria and longterm health risks related to polycystic ovary syndrome (PCOS). Hum Reprod. 2004;19(1):41-47.

4. Azziz R, Carmina E, Dewailly D, et al. Positions statement: criteria for defining polycystic ovary syndrome as a predominantly hyperandrogenic syndrome:an Androgen Excess Society guideline. J Clin Endocrinol Metab. 2006;91(11):4237-4245.

5. Fauser BC, Tarlatzis BC, Rebar RW, et al. Consensus on women's health aspects of polycystic ovary syndrome (PCOS):the Amsterdam ESHRE/ ASRM-Sponsored $3^{\text {rd }}$ PCOS Consensus Workshop Group. Fertil Steril. 2012;97(1):28-38.

6. Cupisti S, Haeberle L, Schell C, et al. ()The different phenotypes of polycystic ovary syndrome: no advantages for identifying women with aggravated insulin resistance or impaired lipids. Exp Clin Endocrinol Diabetes. 2011;119(8):502-508.

7. Panidis D, Tziomalos $\mathrm{K}$, Misichronis $\mathrm{G}$, et al. Insulin resistance and endocrine characteristics of the different phenotypes of polycystic ovary syndrome: a prospective study. Hum Reprod. 2012;27(2):541-549.

8. Lim SS, Davies MJ, Norman RJ, et al. Overweight, obesity and central obesity in women with polycystic ovary syndrome: a systematic review and meta-analysis. Hum Reprod Update. 2012;18(6):618-637.

9. Ezeh U, Yildiz BO, Azziz R. Referral bias in defining the phenotype and prevalence of obesity in polycystic ovary syndrome. $J$ Clin Endocrinol Metab. 2013;98(6):E1088-E1096.

10. Lizneva D, Kirubakaran R, Mykhalchenko K, et al. Phenotypes and body mass in women with polycystic ovary syndrome identified in referral versus unselected populations: systematic review and meta-analysis. Fertil Steril. 2016;106(6):1510-1520.

11. Gosman GG, King WC, Schrope B, et al. Reproductive health of women electing bariatric surgery. Fertil Steril. 2010;94(4):1426-1431.

12. Alvarez-Blasco F, Botella-Carretero JI, San Millan JL, et al. Prevalence and characteristics of the polycystic ovary syndrome in overweight and obese women. Arch Intern Med. 2006;166(19):2081-2086.

13. Laitinen J, Taponen S, Martikainen H, et al. Body size from birth to adulthood as a predictor of self-reported polycystic ovary syndrome symptoms. Int J Obes Relat Metab Disord. 2003;27(6):710-715.

14. Teede HJ, Joham AE, Paul E, et al. Longitudinal weight gain in women identified with polycystic ovary syndrome: results of an observational study in young women. Obesity (Silver Spring). 2013;21(8):1526-1532. 
15. Yildiz BO, Knochenhauer ES, Azziz R. Impact of obesity on the risk for polycystic ovary syndrome. J Clin Endocrinol Metab. 2008;93(1):162168 .

16. Yildiz BO, Bozdag G, Yapici Z, et al. Prevalence, phenotype and cardiometabolic risk of polycystic ovary syndrome under different diagnostic criteria. Hum Reprod. 2012;27(10):3067-3073.

17. Zhao Y, Qiao J. Ethnic differences in the phenotypic expression of polycystic ovary syndrome. Steroids. 2013;78(8):755-760.

18. Chen X, Yang D, Mo Y, et al. Prevalence of polycystic ovary syndrome in unselected women from southern China. Eur J Obstet Gynecol Reprod Biol. 2008;139(1):59-64.

19. Mehrabian F, Khani B, Kelishadi R, et al. The prevalence of metabolic syndrome and insulin resistance according to the phenotypic subgroups of polycystic ovary syndrome in a representative sample of Iranian females. J Res Med Sci. 2011;16(6):763-769.
20. Ladron de Guevara A, Fux Otta C, Crisosto N, et al. Metabolic profile of the different phenotype of polycystic ovary syndrome in two Latin American populations. Fertility and Sterility. 2014;101(6):1732-1739.

21. Practice Committee of the American Society for Reproductive Medicine. Obesity and reproduction: a committee opinion. Fertil Steril. 2015;104(5):1116-1126.

22. Chen $\mathrm{C}$, Jing $\mathrm{G}, \mathrm{Li} \mathrm{Z}$, et al. Insulin resistance and polycystic ovary syndrome in a Chinese population. Endocr Pract. 2017.

23. Al Jefout M, Alnawaiseh N, Al Qtaitat A. Insulin resistance and obesity among infertile women with different polycystic ovary syndrome phenotypes. Scientific Reports. 2017;7:5339. 